\title{
MANIFESTO DOS PIONEIROS de 1932: LEITURAS DE SEUS 80 ANOS
}

Antonio Bosco de Lima ${ }^{1}$

\section{RESUMO}

Este artigo resulta de considerações parciais sobre pesquisa de pós-doutoramento que tem o Plano de Desenvolvimento da Educação como foco central. Na pesquisa global, nosso objetivo geral busca identificar elementos que configurem categorias centrais que sustentam o PDE, considerando a relação público/privado, analisando as manifestações de controle e de regulação do Estado brasileiro presentes neste cenário de políticas educacionais. A investigação, entretanto, nos impulsionou a incluir um panorama dos períodos históricos (1920 a 1937 e 1955 a 1964) nos quais se encontram O Manifesto dos Pioneiros da Educação, datado de 1932 e o Manifesto dos Educadores: mais uma vez convocados, divulgado em 1959, fazendo uma análise da constituição de público e de privado presentes nestes dois Manifestos. Neste artigo, apresentamos dados relativos à investigação sobre o Manifesto dos Pioneiros da Educação de 1932, realizando uma leitura sobre o mesmo, considerando-o como fonte importante e que traduz pela primeira vez na História da Educação um modelo de organicidade que buscou se constituir em Política Educacional, mas que se contrapunha aos movimentos de esquerda do período (anarquismo, socialismo e comunismo).

Palavras-chave: Manifesto dos Pioneiros; público x privado; política educacional.

\section{MANIFEST OF PIONEERS OF EDUCATION OF 1932: REVIEW OF YOUR 80 YEARS.}

\begin{abstract}
This article is a result of the partial considerations about research of $\mathrm{PhD}$ that have the Plan of Education Development (PED) like central focus. In the global research, our general aim wants identify elements that configure central categories that sustain the PED, considering the relation public/private, analyzing the manifestations of control and of regulation of the Brazilian State present in this context of educational politics. Meanwhile, the investigation leads us to include an overview of the historic periods (1920 to 1937 and 1955 to 1964) that we find The Manifest of Pioneers of Education, made in 1932 and The Manifest of Educators: more one time called, exposited in 1959, making an analysis of the constitution of public and of private presents in these two Manifests. In this article, we present ideas referents at the investigation about The Manifest of Pioneers of Education of 1932, making a review about it, considering it like an important fount and that tells for the first time in the Education History an organization model that wanted build itself in Educational Politic, but that was against the left movements of the period (anarchism, socialism and communism).
\end{abstract}

Keywords: Manifest of Pioneers; public x private; educational politic. 


\section{Introdução}

[...] eu não posso compreender radicalmente o presente se não compreender as suas raízes, o que implica o estudo de sua gênese. Foi exatamente a necessidade de compreender mais ampla e profundamente os impasses teóricos da educação brasileira atual que provocou a realização deste trabalho. (SAVIANI, 2010, p. 4).

Este artigo é resultado de relatório parcial de pesquisa pós-doutoral intitulada Plano de Desenvolvimento da Educação: consensos entre público e privado, realizada no âmbito da Faculdade de Educação, no Departamento de História e Filosofia da Educação, da UNICAMP, contando com apoio financeiro do CNPq. Teve início em agosto de $2011 \mathrm{com}$ previsão de conclusão em julho de 2012.

$\mathrm{O}$ foco central da pesquisa tem como objetivo geral identificar elementos que configurem categorias centrais que sustentam o Plano de Desenvolvimento da Educação (PDE), identificados a partir da relação público/privado, analisando as novas manifestações de controle e de regulação do Estado brasileiro presentes neste cenário de políticas educacionais.

A investigação, entretanto nos impulsionou a incluir um panorama, mesmo que breve, dos períodos históricos nos quais se encontram $O$ Manifesto dos Pioneiros da Educação, datado de 1932 e do Manifesto dos Educadores: mais uma vez convocados, divulgado em 1959. Para tanto fizemos uma periodização seguindo Ribeiro (1982).

Quais os elementos que subsidiam as escolhas por determinada periodização? Diversos: os de aspectos pedagógicos, aqueles de cunho político, outros fundados nas fases das políticas sociais. Optamos pelos elementos de base econômica que culminam com os elementos de base social. Não se trata de um determinismo econômico, mas em considerar que o movimento das políticas educacionais está conectado com o movimento políticoeconômico de um país, daí as escolhas, ou disputas, por projetos educacionais, que se configuram em dado projeto de educação.

Ribeiro (1982), em sua "História da educação brasileira", realiza uma periodização da história em 8 momentos ${ }^{2}$. Nossa intenção não é o de abordar a História da Educação em sua completude e sua complexidade, tarefa já realizada com competência por pesquisadores que fizeram uma identificação didática pertinente (dos quais citamos Saviani, 2010; Xavier, Ribeiro e Noronha, 1994; Ghiraldelli Jr., 1994; Romanelli, 1987 e Freitag, 1986). Autores com perspectiva crítica, que adotaram abordagem similar, entretanto focando aspectos mais caracterizados ora pela conjuntura política, ora econômica, ora pelos aspectos pedagógicos.

Intencionamos fazer, por meio de um recorte (período $6^{\circ}$, que abrange os anos de 1920 a 1937 e $8^{\circ}$. período de 1955 a 1964, conforme Ribeiro) uma análise da constituição de público e de privado presente em dois textos essenciais produzidos nestes períodos, $O$ Manifesto dos Pioneiros da Educação Nova (1932) e o Manifesto dos Educadores: mais uma vez convocados (1959).

É importante fazer este destaque, pois, estes dois documentos dizem respeito a um movimento histórico no qual objetivamos entender como estes foram influenciados e influenciadores na sociedade civil e junto aos governos dos períodos. Vale antecipar que no percurso entre os manifestos em tela a Pedagogia Nova enraizou suas práticas influindo com o movimento liberal democrático tanto na sociedade civil, quanto nas políticas educacionais emanadas pelo Estado. 
Na fase que passa pelos anos 1920 e 1930, os Renovadores traziam como teses na Pedagogia Nova um caráter revolucionário, mas se comparada às teses desenvolvidas pela esquerda não passava de reformas, mesmo que estruturais, mas dentro da ordem e de manutenção do sistema e poder econômicos, ou seja, afastavam-se do campo da disputa pelo poder político para intensificarem o "processo de especialização do campo pedagógico". (CUNHA, 1981, p. 12).

"O enraizamento da Escola Nova se processou conforme as ideias liberais, e então se pode dizer que o escolanovismo representou, ortodoxamente, o liberalismo no setor da escolarização." (SANTOS et al., 2006, p. 136). Portanto, o Manifesto de 1932 vem nesta mesma esteira ideológica, política e econômica trazer novas proposituras para uma escola que tem como missão elevar o espírito dos incultos e os bens sociais dos despossuídos, ocasionando uma avalanche de mobilidade social e superação das desigualdades econômicas.

A gênese do Manifesto de 1932 está na Associação Brasileira de Educação (ABE) e nas reformas estaduais dos anos $1920^{3}$. O Movimento Renovador que se inicia neste período toma a ABE como "seu órgão representativo e seu centro divulgador", desencadeando lutas ideológicas que culminam no Manifesto de 1932 e "nas lutas travadas mais tarde em torno do Projeto de Lei das Diretrizes e Bases da Educação Nacional." (ROMANELLI, 1987, p. 129).

Focamos estes manifestos como importantes ações influenciadoras para o campo da História da Educação e das Políticas Educacionais, pois questionam o contexto e a conjuntura de determinados tempos, além de indicarem procedimentos de adequação e superação de mazelas. Muito, eles têm a referendar o modelo atual de educação brasileiro, pois herdamos uma relação constituinte entre público e privado, um republicanismo autocrático pedagógico e as mazelas que ainda convivemos.

Como referenciado, o foco é o PDE, entretanto este estudo historiográfico em política educacional encontra um vínculo estreito entre as artimanhas e articulações expostas na História da Educação. Entretanto, não foi nossa opção estender à temática focando os Manifestos em tela e o PDE. Aproveitamos a deixa do octogésimo aniversário do Manifesto de 1932 e realizamos algumas leituras sobre o mesmo, é o que fazemos a seguir.

\section{O Otimismo e o Manifesto de 1932}

Segundo Ribeiro (1982), o 6º período (1920 a 1937) na História da Educação brasileira é marcado, no campo econômico, pela emergente constituição de um parque industrial. Estávamos adentrando ao modelo nacional desenvolvimentista, baseado na industrialização tardia do país, caracterizada por uma busca em substituir as importações de materiais básicos, bens de consumos imediatos, pela industrialização nacional dos mesmos (a primeira fase da industrialização brasileira).

Esta fase registra os primórdios da tardia Modernização do Brasil, cujo marco é a Revolução de outubro de 1930; entende-se, portanto, que a modernização "está intimamente relacionada com a questão da identificação político-nacional." (BUFFA \& NOSELLA, 1991, p. 60).

A ideia de renovar, padronizar, impor novos modos educacionais e culturais, políticos e econômicos, enfim, sociais, por meio da educação formal, eis a novidade. $\mathrm{O}$ desbravamento progressista de suplantar o velho conservadorismo e as tradicionais formas e conteúdos de ensino; eis o novo. Daí o pioneirismos daqueles educadores, que agora 
olhavam para a America do Norte. "O manifesto pensaria não só a educação, mas o ideário de uma sociedade que deveria modernizar-se e construir uma outra identidade nacional modelada pela educação popular, inserida na vida urbana e industrial." (FILHO, 2012, p. 2179).

Uma nova era econômica e política que requeria um novo paradigma de educação...

Ora, não podia permanecer inalterável um aparelho educacional, cuja base residia uma velha concepção da vida, na sua rigidez clássica, numa época em que a indústria mecânica, aumentando a intensidade, transformou as maneiras de produção e as condições do trabalho, e, criando esse fenômeno novo da urbanização precipitada da sociedade, acelerou as modificações nas condições e nas normas da vida social a que correspondem variações nas maneiras de pensar e de sentir e nos sistemas de ideais e de conceitos. (AZEVEDO, 2010, p. 26).

Trata-se de um período no qual uma nova classe social emerge - uma classe média, formada por funcionários públicos, intelectuais, funcionários do comércio, enfim, a burguesia, que discorda da forma de constituição do governo, porém, concorda com seu conteúdo, ou, conforme Ribeiro "reivindicavam representação e justiça, pois o mal está todo ele na forma como eram escolhidos os mandatários, forma esta que tornava impossível à oposição chegar ao poder." (1982, p. 93).

A educação não se isenta da contextualização do período; a conjuntura educacional dos 1930 estava sendo pressionada pelas classes médias em ascensão que

[...] reivindicavam o ensino médio, e as camadas populares, o ensino primário. Daí porque o movimento renovador compreendeu que havia chegado a hora de o Estado assumir o controle da educação e que, portanto, esta deveria ser gratuita e obrigatória, dadas as necessidades da nova ordem econômica em implantação. (ROMANELLI, 1987, p. 143).

Num Estado combalido que não conseguia aplicar avanços sociais e educacionais, cabe realizar certas mudanças pontuais, no caso da educação, privilegiando o ensino profissionalizante e a educação superior. Entretanto, segundo Ribeiro isto não significa que medidas não tenham sido tomadas no tocante à educação, mas

Quer demonstrar a necessidade e conveniência de que as medidas fossem tomadas em decorrência de um programa educacional mais amplo e, portanto, que tivessem uma unidade de propósitos e uma sequencia bem-determinada de legalização. (RIBEIRO, 1982, p. 100).

Não seria "mais do mesmo", porém havia uma essência neste processo de mudança compactada sob a égide da redenção, do otimismo e do idealismo. "Uma concepção francamente salvacionista convencia-se de que a reforma da sociedade pressuporia, como uma de suas condições fundamentais, a reforma da educação e do ensino. (SHIROMA et al., 2000, p. 17).

Até 1930 a educação configurou-se de forma dualista e elitista. Ensino primário articulado com o ensino profissional destinado aos pobres e ensino secundário com continuidade ao superior, destinado à elite.

Consequência da estrutura federativa da Primeira República, a estrutura de ensino vigente no Brasil até 1930 nunca pudera se organizar como um 
sistema nacional integrado. Ou seja, inexistia uma política nacional de educação que prescrevesse diretrizes gerais e a elas subordinasse os sistemas estaduais." (Ibid, p. 18).

Se os governos, federal e estaduais, iam implementando reformas parcelares, sem uma configuração sistêmica, os debates do período eram salutares, marcados pelo conflito de idéias. Passado o período de agitação das teses esquerdistas, polarizavam católicos e renovadores.

Uma era já tradicional, representada pelos educadores católicos, que defendiam a educação subordinada à doutrina religiosa (católica), a educação em separado e, portanto, diferenciada para o sexo masculino e feminino, o ensino particular, a responsabilidade da família quanto à educação etc. Outra era representada pelos educadores influenciados pelas 'ideias novas' e que defendiam a laicidade, a coeducação, a gratuidade, a responsabilidade pública em educação etc. (RIBEIRO, 1982, p. 104).

Os projetos da Igreja e dos Educadores Novos não contrariavam a ordem das coisas, pois queriam as coisas em ordem. Buscavam, em síntese, hegemonia de suas propostas e articulação co o Estado. "Não existia discordância de fundo entre eles: ambos se adequavam cada um a seu modo, às relações sociais vigentes e nem um nem outro se colocavam em questão." (SHIROMA et. al., 2000, p. 22).

O que unificava tais educadores centrava a tese da liberdade de educação. Aqueles "educadores, de ambos os grupos, entretanto, eram unânimes em combater o princípio de monopólio do ensino pelo Estado, colocando-se, assim, contra as ideologias tanto de esquerda (comunismo) como de direita (fascismo)." (RIBEIRO, 1982, p. 104).

Para a Igreja, a educação moral do povo brasileiro deveria ser de sua exclusiva competência. Tratava-se, para os católicos, de um esforço político, patriota, uma vez que colaborando para a pureza dos costumes, estaria formando homens úteis e conscientes, com os conhecimentos necessários aos bons cidadãos. (SHIROMA et. al., 2000, p. 20).

Os liberais-elitistas e os igualitários polarizaram com os católicos e enquanto atuantes em seus papéis de "governos" procuraram instaurar um modelo de política educacional, ou dele foram anuentes, relativizando propostas mais radicais. Dentro da ordem assumiram uma postura de pioneiros ou de vanguarda, portadora da verdade libertadora dos povos pobres e ignaros, se colocaram como porta-vozes da população e em nome dela falaram, pois "acreditavam (com diferentes ênfases) que a educação devia e podia atender a todos identicamente se assumida por um Estado supranacional, baseado na ciência neutra, incontaminado dos interesses econômicos e sociais classistas." (WARDE, 1982, p. 10). Afinal a educação estava acima (ou deveria estar) dos interesses políticos, individuais e anti-sociais.

Ou seja, existia uma unidade na defesa da liberdade total da escolha e o direito de escolha (da família), porém os setores liberais (liberais elitistas e liberais igualitaristas) se afastavam dos ideais católicos ao defenderem a liberdade fiscalizada, e, portanto, uma centralidade de controle organizacional por parte do Estado, ou seja, uma "responsabilidade pública em educação." (RIBEIRO, 1982, p. 104).

Até determinado momento liberais e católicos "participavam, lado a lado, na Associação Brasileira de Educação (ABE). O conflito emergiu no apagar das luzes de 1931, na IV Conferência Nacional de Educação, vindo a consumar-se a ruptura com a 
publicação do 'Manifesto dos Pioneiros da Educação Nova', no início de 1932." (SAVIANI, 2010, p. 197).

Podemos traduzir tais embates em um pano de fundo que reflete a essência de tais lutas, nada revolucionarias, mas modernas, no sentido de trazerem certas mudanças para um país com portentoso atraso. "Na realidade, a luta estabelecia-se entre diferentes formas, 'conservadora' versus 'moderna', de defesa de interesses sempre particulares." (RIBEIRO, 1982, p. 106).

O problema da nova sociedade (pós-revolução de 1930) centrava-se nas mudanças políticas, a economia era tangida pelas necessidades internas e pela crise internacional, quanto à educação

A realidade, porém, é que o movimento não tinha essa sinceridade revolucionária. A educação do povo não era problema estrutural da nova sociedade brasileira em processo de democratização, mas contingência que se tinha de remediar, de forma mais aparente do que real, e daí permanecer o nível aceitável como mínimo, na época, até hoje [...]. (TEIXEIRA, 1994, p. 93).

As medidas tomadas pelo Governo Provisório, chefiado por Getúlio Vargas, logo em seu início, tinha caráter organizativo cunhado em propostas escolanovistas, mas voltavam-se especialmente para a organização da Educação Superior e do controle da educação nacional. Segundo Lemme, as "providências do governo revolucionário, apesar de muito importantes, podiam ser consideradas como fragmentárias e mantinham o mesmo critério anterior do governo federal continuar alheio aos problemas do ensino popular, de $1^{\circ}$. e $2^{\circ}$. Graus, tal como acontecia na vigência da Constituição de 1891"'. (2004b, p. 173).

A tese central de Romanelli sobre a expansão do ensino, após 1930, diz respeito à quantidade e qualidade. O crescimento do ensino após 1930 foi resultado

[...] de dois fatores concomitantes: o crescimento demográfico e a intensificação do processo de urbanização. O primeiro é responsável pelo crescimento da demanda potencial de educação e o segundo, pela evolução dessa demanda, que se torna aos poucos demanda efetiva. (ROMANELLI, 1987, p. 14).

Entretanto, marca-se pela contenção, elitizada da educação, o que constrange a quantificação de um número de escolas que atendam os necessitados por escola pública. Ou seja, por um lado a contenção da ampliação e por outro a busca de superação de um modelo arcaico, tradicional de educação por uma Pedagogia Nova, esclarecedora e formadora de um sujeito eminentemente qualificado e empreendedor.

Ou seja, o Movimento renovador que deságua suas potencialidades no projeto político do Manifesto de 1932 "esclarece" que "A sua luta era contra a escola tradicional, não contra o Estado burguês." (Ibid, p. 151).

A Escola Nova, centrada nos recursos da Pedagogia Nova está carregada de idealismo. "[...] para o movimento da Escola Nova, a transformação social se daria pela educação.” (BUFFA \& NOSELLA, 1991, p. 62).

A ação dos Pioneiros busca apoio e apoiar o governo provisório. Combatendo um ensino tradicional e academicista, voltado para as elites eles se tornam verdadeiros desbravadores no campo educacional, são, portanto progressistas para a época, embora acentuadamente idealistas, principalmente, no que diz respeito ao seu "evolucionismo econômico e ingenuidade política." (Ibid, p. 65). 
O idealismo é coadunado com a ingenuidade de um Estado protetor. "Ao lado da crença no desenvolvimento econômico, é apontada, também, uma forte dose de ingenuidade política que fazia co quem os educadores dessa época acreditassem no Estado, aceitando colaborar com ele para viabilizar as proposta educacionais." (Ibid, p. 65-66).

Entretanto, se o projeto liberal-democrático se consistia na busca da qualificação da educação voltada para uma contenção quantitativa, tal projeto ia de encontro às demandas efetivas que se colocavam na ordem do dia.

As mudanças requeriam um homem urbanizado, educado, mas necessariamente não requeria a formação para o trabalho. A forma de industrialização em vigor não requeria uma formação escolar rígida, visto que "Nesta fase da industrialização era possível treinar os operários rapidamente nas próprias fábricas.” (RIBEIRO, 1982, p. 114).

Talvez isto explique os elementos diferenciadores dos defensores do Entusiasmo Educacional e dos Otimistas Pedagógicos. Os primeiros com olhar em uma educação préindustrialização que requisitava ampliação na formação de alfabetizados e os segundos centrados na formação de um homem para um novo mundo educado e democrático cuja essência estaria na Europa e no EUA.

O movimento "novista", com base no Otimismo, diz respeito às condições consensuais das reformas. Ampliar preceitos de liberdade, mantendo-se a estrutura capitalista. Daí uma tese renovadora, porém idealista, reformista, portanto,

Ao proporem um novo tipo de homem para a sociedade capitalista e defenderem princípios ditos democráticos e, portanto, o direito de todos se desenvolverem segundo o modelo proposto de ser humano, esquecem o fato fundamental desta sociedade que é o de estar ainda dividida em termo de condição humana entre os que detêm e os que não detêm os meios de produção, isto é, entre dominantes e dominados. (Ibid, p. 116).

A educação como um processo social, porém, que encarna sobre os indivíduos e não a educação que esclarece a sociedade, ou que considera a sociedade dividida em classes. A organização da sociedade é ao que parece, uma soma de sujeitos e de coisas, que, sendo organizadas, desempenham um papel saudável na engrenagem biológica social.

A centralidade na educação é um dos princípios fundamentais daqueles que defendem a tese liberal-democrática. Nesta vertente a democracia é preceito resultante da educação. A democracia não antecede a educação. É na e pela educação que se forjam os ideais e as práticas democráticas. Portanto, ampliar não basta, mas é preciso qualificar a educação.

Vejam que a escola recebe em seus ombros uma cruz universal e que para conduzila pelo caminho do martírio precisaria ser super dotada ou mística.

É imperioso afirmar que neste nosso tempo, como o tempo passado, educação não é central para o capitalismo, mesmo assim, o Otimismo dos educadores novistas, embora idealista, tiveram um aspecto importante

$\mathrm{O}$ aspecto positivo resultante de mais este transplante cultural está no fato de ter levado os educadores a diagnosticar as deficiências da estrutura escolar brasileira e a denunciá-las categórica e permanentemente, como forma de demonstração de que a reforma, cujo plano adequado acreditavam ter, era uma necessidade imperiosa. (RIBEIRO, 1982, p.117)

Mas, daí achar que a escola é a solução para os disparates da sociedade capitalista é de um idealismo hiper avançado. A educação é essencial, porém ela é parte - ela por si não 
resolve o problema da distribuição e concentração de rendas - esta sim é o pior malefício da vida econômica, social, cultural, política e educacional do povo brasileiro.

Nenhum país avança e nenhuma sociedade se torna verdadeiramente democrática, sem uma escola cidadã de qualidade que inclua todos, sem discriminação ou formas de preconceitos que agridem o propósito de desenvolvimento humano integral. (HADDAD, 2010, p. 103).

Trata-se da velha tese liberal da liberdade de escolha e da igualdade de direitos, e, portanto, ao invés de tocar na concentração de rendas e de sua desequilibrada distribuição, toma a escola como pedra angular das transformações, da possibilidade de ascensão social.

Numa sociedade como a nossa, tradicionalmente marcada pelo profundo espírito de classe e de privilégio, somente a escola pública será verdadeiramente democrática e somente ela poderá ter uma programa de formação comum, sem os preconceitos contra certas formas de trabalhos essenciais à democracia. (TEIXEIRA, 1994, p. 101).

A questão central, portanto, para os escolanovistas centrava-se na educação. Entende-se a escola como uma possibilidade de ser oásis no deserto das desigualdades sociais, nas desigualdades de poder, no deserto, composto pela autocracia e centralização. Daí entender o processo revolucionário hegemônico (anos 1930) e o modelo de política educacional em construção. O cenário político maior estabelecia uma disputa entre teses sociais e políticas. "De um modo geral, podemos dizer que liberais, católicos e os governos desejavam transformações 'dentro da ordem', enquanto integralistas e aliancistas se debatiam por transformações que levassem a uma 'nova ordem'." (Grifos do autor) (GHIRALDELLI JR., 1994, p. 41).

A conjuntura muda após os anos de revolução (1930). "O desenvolvimento brasileiro, após 1930, parece-nos, mostrou suas falhas, notadamente pela incapacidade de a sociedade, como um todo, levar a cabo, de modo mais coerente e integrado, sua revolução burguesa." (ROMANELLI, 1987, p. 83).

Politicamente o país muda. As forças dantes hegemônicas concentradas na agricultura, na oligarquia dos cafeicultores sofrem revezes. "[...] se o que resultou politicamente da Revolução de 1930 foi um 'Estado de compromisso', caberia considerar que esse Estado se pôs como agente, no plano governamental, da hegemonia da burguesia industrial." (Grifos do autor) (SAVIANI, 2010, p. 193).

A essência da expansão do ensino pós-1930 teve uma tendência marcada pela disputa na efetividade, visto por um lado "os interesses das camadas populares por mais educação, e educação que assegurasse status, e (por outro) os interesses das classes dominantes, que procuravam conter, de várias formas possíveis, as pressões dessas camadas." (ROMANELLI, 1987, p. 104).

Fica bem nítido, neste episódio, a função da educação como fundamento ideológico, como formação de mentalidades, portanto, formando, por um lado classe dirigente, e por outro contendo a escolarização dos filhos das camadas pobres da população.

Sobre o tempo político e social do Manifesto de 1932, destaca-se forte tendência de concentração de rendas causando enorme desigualdade social. Como mudar a educação se a elite concentra em suas mãos o poder de governo e influencia a sociedade a manterem-se disciplinadas? 
Anísio identificava essas resistências também na forma como nosso processo político tinha se organizado, cristalizando a tendência dos políticos profissionais utilizar o espaço público e o poder público como instrumento de defesa dos interesses privados, o que conduzia a uma política clientelista e personalista. (SAVIANI, 2010, p. 222).

Após 1930 novas camadas sociais entram em cena. Porém, se há necessidades expostas destes sujeitos por políticas sociais, dentre elas as educacionais, o Estado se mantém conservador e controlador no que diz respeito ao atendimento de tais demandas.

Como vimos anteriormente, trata-se de um embate entre o velho e o novo. O novo carrega do velho uma nova forma de mandonismo e de neoconservadorismo. Isso no Brasil reflete com o crescimento da economia, que nos anos $30 \mathrm{em}$ diante, envolveu

[...] setores mais modernos e dinâmicos da sociedade, acabou gerando o rompimento com a velha ordem política. E esse rompimento significou não uma destruição da velha estrutura econômica e social, mas apenas a expansão do setor moderno e a emergência de novas camadas sociais. (ROMANELLI, 1987, p. 110).

Um novo país por uma nova educação - formar o novo homem que irá engendrar a nova sociedade. Este é o espírito empreendedor que situa a educação na Revolução de outubro de 1930, "propõe o abandono de um passado visto como atrasado, como representação do velho, e enfatiza a perspectiva do nascimento de um País Novo." (MUELLER , 2012, p. 230-231).

Consequente a este padrão de mudança e permanência do velho, na educação as transformação se mostraram "inconsistentes, insuficientes e inadequadas, já que visaram, sobretudo, à expansão das oportunidades educativas que existiam para as camadas privilegiadas.” (ROMANELLI, 1987, p. 110).

A essência deste movimento consiste em uma constante intervenção governamental na contramão das demandas por educação. Além da disparidade entre a questão social ampla e as forças de desenvolvimento do país, o movimento renovador não atentou para a questão do modelo de democracia que se tentava construir no país.

Para Lemme, o Manifesto de 1932 "pressupunha a existência de uma sociedade homogênea e democrática, regida pelo princípio fundamental da igualdade de oportunidade para todos." (2004b, p. 178). Percebemos uma boa idealização de relação social, mas ingênua ao assimilar igualdade de fato em um país que adentra ao modelo capitalista de produção e relação social. A efetividade e a potencialidade do Manifesto de 1932 e por isso a sua dificuldade de implementação, pois se pressupõe uma sociedade política e economicamente avançada, o que 80 anos após sua divulgação ainda não construímos.

\section{Formar o novo homem para formar uma nova sociedade: O Manifesto de 1932}

O Manifesto dos Pioneiros da Educação apresenta uma riqueza e sutileza de elementos que provocaram uma série de estudos e problematizações ${ }^{4}$, os quais, importantes para a compreensão do processo histórico educacional brasileiro, não serão abordados neste trabalho. Estudos vários já foram realizados sobre ele, flagrando as questões sobre o posicionamento católico, a laicidade do ensino, a co-educação, ensino público-estatal, os signatários das vertentes liberais e socialistas, enfim, um caixa de pandora para os 
estudiosos da educação que ainda não foi totalmente exposto. Para nós interessa neste momento averiguar a composição conceitual e a relação entre público e privado.

A tese que vai se estabelecendo hegemonicamente não toca em mudanças radicais na sociedade, mas é voltada para o indivíduo. As transformações ocorrem a partir do sujeito, o que parece impulsionar as mudanças na sociedade. Daí investir as ações na formação do homem, o que significa centrar forças na educação.

Não se trata de um indivíduo isolado, abandonado, trata-se de um indivíduo com direitos, vivo, e que emana de seus atos e feitos um resultado coletivo.

Se a escola tradicional mantinha o indivíduo na sua autonomia isolada e estéril, a nova educação, embora pragmaticamente voltada para os indivíduos e não para as classes, fundando-se sobre o princípio da vinculação da escola com o meio social, forma para a cooperação e solidariedade entre os homens. (SAVIANI, 2010, p. 244).

Trata-se de colocar a questão social, que já aparecera na Europa do século XVIII como questão crucial, não do Estado, mas da Educação, mesmo que tardiamente, no Brasil, que se moderniza. Um dos elementos de "sobriedade" para a existência da burguesia está em atender fragmentadamente, e incorporar os sujeitos trabalhadores nas políticas sociais. Isto não é obra do anarquismo, nem do socialismo tampouco do comunismo, mas do capitalismo. É claro que os defensores desta tese esquecem-se de incorporar nesta história o movimento dos trabalhadores.

Provavelmente seja no Brasil a primeira vez que a estola toma tal dimensão. A dimensão de ter responsabilidade social.

\begin{abstract}
A integração da escola no meio social a que se mantinha estranha; a sua adaptação aos problemas imediatos e à natureza de cada região a sua organização interna, em bases novas, como uma escola de trabalho, e a ampliação de sua função docente uma larga função educativa e social, capaz de erguê-la à altura de um centro vital da comunidade, aparelharam a escola, como um poderoso fator social, para atender progressivamente às exigências das rápidas transformações que se operam nas sociedades moderna, e para contribuir mais eficazmente para o aperfeiçoamento do meio social. (AZEVEDO, 1948, p. 252).
\end{abstract}

Isto lembra a tese central da Riqueza das Nações, de Adam Smith (1983), nações ricas são resultado de homens poupadores e empreendedores. Portanto resulta das intenções individuais.

A educação como questão social e de possibilidade de alavancar o progresso, democratizando assim a sociedade é referência para os associados da $\mathrm{ABE}$, os quais irão estabelecer como um dos momentos culturais e de debates sobre a educação, buscando formar novas mentalidades, as Conferências Nacionais de Educação (CNE) ${ }^{5}$. Estas têm maior incidência impar entre os anos 1920 e 1930.

Sobre as Conferências de Educação Cunha afirma que elas "constituem um momento do processo de organização do campo educacional: o momento de consciência da especialidade da educação, em particular da educação escolar”. (1981, p. 6).

Menção atual pode ser realizada ao colocarmos em pauta a IV Conferência, que ocorreu em 1931, da qual se originou o Manifesto de 1932. Ocorria naquele momento forte centralização do Governo em exercício, chefiado por Getúlio Vargas, e que mostra que a desmobilização da sociedade civil mobiliza a organização do Estado, o qual procura novos 
parceiros junto à organização empresarial. "Clássica cilada política que o Estado brasileiro arma para os educadores: aparenta solicitar direção da política educacional, quando, na verdade, visa, assim, impedir a organização autônoma e de base da categoria dos educadores." (BUFFA \& NOSELLA, 1991, p. 67).

A menção atual a que nos referimos situa o movimento do MEC nos anos de 2005 a 2007 aglutinando parcela da sociedade comercial organizada para o projeto de educação intitulado PDE, que teve uma ampla influência dos empresários de vários setores e de organizações não governamentais ligados às indústrias variadas.

Para a literatura da área a IV CNE foi, sem dúvida, a mais polêmica, ela teve como objetivo debater a solicitação do Governo Federal sobre novas diretrizes para uma política nacional de educação. Tal conferência marca um momento de explicitação de projeto educacional.

Se os educadores leigos e os confessionais vinham numa espécie de trégua e fraternidade ai foi o momento de ruptura. No decorrer da Conferência

Sucessivos oradores defendiam posições a favor e contra a laicidade da escola pública, evidenciando a impossibilidade de os educadores atenderem de fato ao apelo aparente do ministro. A conferência terminou, assim, num impasse, com a expectativa de retomada das discussões na conferência seguinte. (CUNHA, 1981, p. 15).

Mas não foi uma drástica ruptura, pois não houve vencedores, os Renovadores continuaram a militar na $\mathrm{ABE}$, prosseguindo com influências sobre o campo pedagógico e os Católicos a defenderem seus ideais na recém criada Associação Educacional Católica (AEC), que tinha como tese a liberdade de ensino, a obrigatoriedade do ensino religioso em todas as escolas e, é claro, o financiamento público para suas escolas.

A IV Conferência serviu como um divisor de águas entre católicos e liberais. Na tentativa de influenciar as diretrizes governamentais, os liberais vieram a público, em 1932, com o célebre 'Manifesto dos Pioneiros da Educação Nova', um longo documento dedicado ao governo e à nação que pautou-se em linhas gerais, pela defesa da escola pública obrigatória, laica e gratuita e pelos princípios pedagógicos renovados[...] (GHIRALDELLI JR., 1994, p. 42).

A abertura da IV Conferência foi realizada sob a Presidência do Chefe do Governo Provisório Getúlio Vargas, o qual. Mais incisivo que o Ministro Francisco Campos da recém criada pasta do Ministério da Educação e Saúde,

[...] solicitou aos conferencistas que colaborassem com o governo provisório na definição da política educacional, que buscassem "por todos os meios a formula mais feliz" para a "unidade da educação nacional", sob a promessa de obterem todo ampara da administração sob sua chefia. (Grifos da autora) (WARDE, 1982, p. 8).

Da convocação e da realização pela $\mathrm{ABE}$ da IV CNE resultou duas iniciativas: a) um "convênio estatístico entre o governo federal e os estados para adotar normas de padronização e aperfeiçoamento das estatísticas de ensino, em todo o País [...]” e b) a "elaboração de um documento em que os mais representativos educadores brasileiros, atendendo a solicitação do chefe do governo revolucionário, procurariam traçar as 
diretrizes de uma verdadeira política nacional de educação e ensino, abrangendo todos os seus aspectos, modalidades e níveis". (LEMME, 2004b, p. 174). Estas duas proposições deram cunho histórico a $\mathrm{ABE}$, mas, mais que isto, forjaram um modelo de organização educacional pela primeira vez na história da educação do Brasil.

O Manifesto de 1932, na esteira do escolanovismo, continha três bases: a econômica, na qual se rogava a ampliação do desenvolvimento industrial, que substituiria o setor agroexportador, isto influiria numa proposição de modernidade, superando-se o conservadorismo até então presente; o aspecto político era relevante e estava incluso numa proposta pedagógica de desenvolvimento no sujeito e de escola como uma questão social, que iria enquadrar a política e a economia, por via da construção democrática, e, finalmente a questão educacional, na qual se tratava a educação como elemento formador do cidadão e da formação de mão-de-obra adequada para o mercado em construção.

O Manifesto de 1932 "representa, efetivamente, a ideologia dos renovadores. É a afirmação de uma tomada de consciência e um compromisso. Mas, justamente por refletir as incoerências do período, o Manifesto exibe também suas inconsistências." (ROMANELLI, 1987, p. 145). Uma dessas inconsistências trata da adoção da preocupação por grandes problemas nacionais, com o desenvolvimento do país, entretanto, seus encaminhamentos estão sujeitos a uma visão "liberal e idealista dos educadores românticos do século XIX." (Ibid, p. 145). Ou seja, observa-se uma "boa dosagem de otimismo e confiança nos poderes da educação [...]”. (Ibid, p. 146).

O documento configura-se como uma primeira tentativa de política educacional, pois apresentava noção de sistema e organicidade, articulação e criteriosidade, concepção pedagógica e diretiva da organização racional do trabalho, enfim situava gestão educacional e gestão escolar. Suas manifestações no campo da organização pedagógica implicavam em um modelo de estruturação de reforma da educação com consequente reforma da sociedade.

Em torno de um projeto de educação nacional aglutinou-se um grupo bastante heterogêneo, o que caracteriza o ecletismo intelectual presente no Manifesto.

O grupo responsável pelo 'Manifesto' nada tinha de homogêneo. O termo liberal, utilizado constantemente para designá-lo, é apenas um arcabouço formal que abrigou liberais elitistas como Fernando de Azevedo e Lourenço Filho e liberais igualitaristas como Anísio Teixeira. (Grifo do autor) (GHIRALDELLI JR., 1994, p. 42).

Entretanto, se haviam razões ideológicas conflituais no grupo, estas não chegavam a se transformarem em contradições, pois, que, se alinhavam em torno de um projeto educacional que pouco revelava o campo da econômica e das contradições de classe.

Se os pioneiros tiveram importância salutar no período de 1930, conquistando no período posterior a implementação de suas bases pedagógica, é válido ressaltar que isto não aconteceu sem o impedimento de que outras correntes, principalmente as conservadoras continuassem manifestando suas concepções, mas é preciso também frisar que sua proximidade com os governos

[...] contribuiu e muito, mesmo sem o perceber e mesmo sem o querer de muitos de seus membros, para o abafamento e exclusão de outras perspectivas ideológicas capazes de acionar as mesmas defesas educacionais de uma forma politicamente mais avançada, capazes de colocar devidamente as questões educacionais no interior de uma análise 
concreta das condições econômicas, sociais e políticas do Brasil. (WARDE, 1982, p. 10).

Uma das primeiras advertências contidas no Manifesto de 1932 trata da descontinuidade e desunidade dos planos como causa das mazelas educacionais. O Manifesto de 1932 destaca como questão preponderante para as mazelas educacionais acumuladas as reformas parciais e descontínuas, apontando uma proposição de superação por meio de uma verdadeira reforma que se descortina via educação nova, pois em "cada uma das reformas, em que impressiona vivamente a falta de uma visão global do problema educativo". (MANIFESTO de 1932, 2006, p. 190).

O Manifesto de 1932 absorve os aspectos centrais da educação nova: a) a técnica/prática/pragmatismo; b) o biologismo, significando a capacidade de cada um; c) educação focada no indivíduo e não a uma classe; d) formação democrática, porém construída a partir de uma hierarquia de capacidades.

Estas teses focais carregam contradições incorrigíveis. Primeiro que é ideologizar a educação acima das lutas de classe, como se neutra ela fosse, portanto na sequência, ser a educação uma questão social, ou seja, a sociedade está constituída por indivíduos individuais e não por sujeitos coletivos. Reforça tal tese ao estabelecer o princípio biológico, no sentido da capacidade de cada um e da necessidade da educação. Esta dualidade, indivíduo e social, pode ser explicada pelo fator da concepção de coletivo para o liberalismo, que seria a soma das partes, mas também pelas próprias ideias dos liberais igualitaristas, que vêem na educação um laboratório para a democracia e para a afinidade coletiva.

A educação é dever do Estado, porém é o indivíduo o responsável por sua educação integral, daí a prevalência da família, portanto trata-se de uma educação pública, porém "com a cooperação de todas as instituições sociais." (Ibid, p. 192).

$\mathrm{Na}$ sociedade moderna, a família, de centro produtor passou a ser centro de consumo, logo, foi perdendo características de educadora, nada mais lógico, portanto do que ela aglutinar seu poder de delegação no qual deve preponderar o direito de escolha.

Tal recorrência à família é algo muito presente no modelo de educação liberal, que institui modos de articulação e relação escola-comunidade.

[...] o Estado, longe de prescindir da família, deve assentar o trabalho da educação no apoio que ela dá á escola e na colaboração efetiva entre pais e professores, entre os quais, nessa obra profundamente social, tem o dever de restabelecer a confiança e estreitar as relações, associando e pondo a serviço da obra comum essas duas forças sociais - a família e a escola, que operavam de todo indiferentes, senão em direções diversas e às vezes opostas. (Ibid, p. 193).

A convivência harmoniosa ente público e privado também se constitui nesta busca pela construção consensual e progressista na qual a família e a comunidade foram conclamadas a contribuir com a escola. O teor do Manifesto de 1932 é bem claro nesta busca de unidade ao explicitar que em "nosso regime político, o Estado não poderá, de certo, impedir que, graças à organização de escolas privadas de tipos diferentes, as classes mais privilegiadas assegurem a seus filhos uma educação de classe determinada [...]" (2006, p. 193).

Por dois motivos, pela liberdade de oferta distinta, o que permite a liberdade de escolha, mas também pela convivência harmoniosa entre público e privado fazerem parte das sociedades tolerantes e modernas. Assim é que Teixeira conclama que "Não 
advogamos o monopólio da educação pelo Estado, mas julgamos que todos têm direito à educação pública, e somente os que o quiserem é que poderão procurar a educação privada". (1994, p. 101). Ou seja, modelos de oferta de educação coexistentes, com financiamentos, a princípio, distintos. Talvez com um mirante de que a educação pública venha a ter a mesma uma expansão ampla e a mesma qualidade da educação privada.

Outro condicionante para as mazelas educacionais acumuladas refere-se à obrigação de manutenção da educação sob os auspícios do Estado. Teor semelhante encontramos no tempo presente, incorporado nos princípios presentes no Plano de Desenvolvimento da Educação (PDE 2007), e que, sabiamente Haddad (2008), ao articular com o empresariado, submeteu o PT e as instituições/associações professorais e estudantis que apóiam o Partido a uma lógica prounesca e tecnicista. Vejamos o teor do Manifesto de 1932, "Mas, subordinada a educação pública a interesses transitórios, caprichos pessoais ou apetites de partidos, será impossível ao Estado realizar a imensa tarefa que se propõe de formação integral das novas gerações." (2006, p.194).

As diferenças inatas estão postas no Manifesto de 1932. E isto naturaliza um sistema que deve oferecer uma base qualitativa para todos, entretanto, atendendo a aptidões individuais, corroborando o dualismo do ensino secundário. Foi o que vimos recentemente com o decreto $2.208 / 97^{6}$ e é o que estamos vendo agora com a formação técnica e tecnológica que busca incorporar alunos do Ensino Médio ao mundo do trabalho.

As Universidades são elevadas como fonte de solução dos problemas culturais, sociais e políticos. Trata-se de uma educação como centro de todos os movimentos. Referenda o Manifesto de 1932 “A organização das Universidades é, pois, tanto mais necessária e urgente quanto mais pensarmos que só com essas instituições, a que cabe criar e difundir ideais políticos, sociais, morais e estéticos [...]” (2006, p. 199).

Nada mais liberal democrático do que alimentar a igualdade entre os desiguais, focando a Educação Superior como elemento primordial de formação e seleção entre os sujeitos. Segundo o Manifesto de 1932, essa

[...] seleção que se deve processar não 'por diferenciação econômica', mas 'pela diferenciação de todas as capacidades', favorecida pela educação, mediante a ação biológica e funcional, não pode, não diremos completar-se, mas nem sequer realizar-se senão pela obra universitária [...]. (Grifos no original) (2006, p. 199).

O teor de doutrinamento é fundamental no movimento em defesa da educação dos anos 1930, e o Manifesto de 1932 incorporou muito bem este princípio. A sociedade precisa ser convencida do papel essencial da educação. Naquele momento histórico, como no tempo presente encontramos tese similar no PDE 2007.

É preciso, certamente, tempo para que as camadas mais profundas do magistério e da sociedade em geral sejam tocadas pelas doutrinas novas e seja esse contato bastante penetrante e fecundo para lhe modificar os pontos de vista e as atitudes em face do problema educacional, e para nos permitir as conquistas em globo ou por partes de todas as grandes aspirações que constituem a substância de uma nova política de educação. (MANIFESTO de 1932, 2006, p. 202).

Como desenvolvimento doutrinário busca convencer a opinião pública do melhor método e metodologia, a escola nova. Esses traços doutrinários podem ser encontrados no PDE. O caráter de "manifesto que procura angariar adeptos junto à opinião pública, o que 
geralmente implica concessões em detrimento da pureza doutrinária." (SAVIANI, 2010, p. 252).

O que parece é que a sociedade civil não tem lucidez dos problemas da educação. Principalmente a classe trabalhadora que sofre carências educacionais. É como se ela vivesse o problema educacional, mas não tivesse consciência do mesmo. Trata-se de tomar a sociedade civil como apática, receptora de novas ordens pedagógicas, políticas, sem refletir sobre as mesmas. Gadotti, no seu "Convocados, uma vez mais" (2008) fecha com tal proposição ao afirmar que o PDE 2007 está sendo implementado, cabendo à sociedade contribuir para o seu aprimoramento.

Trata-se de uma classe esclarecida que precisa convencer a população sobre o mais adequado remédio contra os malefícios sociais. O engajamento com a educação, e esta como forma de superação das mazelas educacionais e culturais reclama por um sujeito educador que esteja além do seu tempo e além dos seus contemporâneos.

Azevedo conclama que

Só nos educadores, a obra e a vida precisam oferecer uma grande unidade; e nada é possível esperar de duradouro daqueles que não aprenderam se não toda a técnica de sua arte, ao menos todo o respeito ao seu ideal. Nem todos podem colher os frutos da obra que realizam. É preciso muitas vezes semear, sem a esperança de participar na colheita; uns preparam e tornam o terreno favorável à germinação da semente; [...] Mas essa obra, por isto mesmo, por ser mais pura e desinteressada, não é mais generosa e mais bela? (1948, p. 255).

Vemos aqui uma verdadeira manifestação a uma profissão de fé, esperança e utopia, que conclama a resistência ao complô universal que busca desmontar e desmobilizar aqueles que têm o ideal e a pureza de levar ao povo a educação e a cultura que os libertarão da opressão política e econômica.

Pela organização ordeira serão estabelecidos novos conceitos e transformações sociais que se operam a partir da educação. A democracia é uma construção que se realiza e se processa pela e na educação. Reproduz-se uma verdade absoluta na qual homens esclarecidos e educados constroem uma sociedade humanizada. Ora, é claro que há fundamento nisto, entretanto, não é somente pela educação formal que isto ocorre, mas pela educação ampla, na qual o indivíduo é sujeito de sua história. E mais, é preciso considerar os avanços do modo de produção e sua relação com a sociedade.

Mészáros (2005, p. 76) identifica a educação e suas mudanças numa perspectiva ampla, "A transformação social emancipadora radical requerida é inconcebível sem uma concreta e ativa contribuição da educação no seu sentido amplo [..]" Este raciocínio é conclusivo a partir de sua critica aos limites da educação formal, que se distancia da formação integral do homem, visto ser "quase impossível dentro dos estreitos limites da educação formal, tal como ela está constituída em nossa época, sob todo tipo de severas restrições." (2005, p. 58).

Entretanto, o Manifesto de 1932 se configura a partir de concepções distintas de transformação social, pois que está imbuído numa "revolução" liberal democrática,

[...] as únicas revoluções fecundas são as que se fazem ou se consolidam pela educação, e é só pela educação que a doutrina democrática, utilizada como um principio de desagregação moral e de indisciplina, poderá transformar-se numa fonte de esforço moral, de energia criadora, de solidariedade social e de espírito de cooperação. (2006, p. 203). 
Além da distinção sobre a transformação social, observamos também uma distinção sobre a educação, no campo restrito e no campo amplo.

E se conclui o manifesto, assinado por 21 intelectuais representativos do período, elegendo a educação como causa maior, central, e mobilizadora das consciências e ações dos homens.

[...] o dever mais alto, mais penoso e mais grave é, de certo, o da educação que, dando ao povo a consciência de si mesmo e de seus destinos e a força para afirmar-se e realizá-los, entretém, cultiva e perpetua a identidade da consciência nacional, na sua comunhão íntima com a consciência humana. (MANIFESTO de 1932, 2006, p. 203).

O Manifesto de 1932 teve uma influência salutar nos destinos da legislação que regem a educação, creditando na Constituição Federal de 1934 um teor voltado para a organização educacional nacional. Porém, com "o estabelecimento do Estado Novo, em 1937, as lutas ideológicas em torno dos problemas educacionais entraram numa espécie de hibernação [...]." Dentre outros motivos porque aquilo que na "Constituição de 1934 era um dever do Estado passa, na Constituição de 1937, a uma ação meramente supletiva." (ROMANELLI, 1987, p. 153).

Com a instalação do Estado Novo é preciso manter um equilíbrio a "consensualidade" forçada, na harmonia das ações do governo, aproximando católicos e renovadores.

Dir-se-ia que a 'modernização conservadora', conceito com que a historiografia tende a classificar a orientação política que prevaleceu após a Revolução de 1930, poderia facultar a seguinte leitura: enquanto conservadora, essa orientação buscava atrair a Igreja para respaldar seu projeto de poder; enquanto modernização, a força de atração dirigia-se aos adeptos da Escola Nova. Estes eram vistos como portadores dos requisitos técnicos necessários à viabilização do projeto de modernização conservadora. (Grifo do autor) (SAVIANI, 2010, p. 270-271).

Escrevendo sobre o Manifesto de 1932 e a conjuntura social do período Lemme, após 50 anos do lançamento do Manifesto, afirma que "a situação em relação aos problemas básicos da educação e do ensino agravaram-se [...]” (2004b, p. 180).

Trata-se de um lúcido aspecto analisado por Lemme, que nenhuma Pedagogia ou Escola Nova conseguiu romper, pois se refere a um câncer que vai corroendo nossos jovens de origem pobre e alimentado os filhos da elite. Persegue o autor

[...] essa situação decorre, fundamentalmente, do fato da estrutura da sociedade brasileira continuar a ser profundamente antidemocrática. E isto é facilmente comprovável em face dos dados oficiais sobre a concentração da renda no País, especialmente nos últimos anos, pelos quais se verifica que uma minoria de brasileiros vem se tornando cada vez mais rica, enquanto a maioria do povo se empobreceu gradativamente. (2004b, p. 180).

Em esteira contrária às perspectivas escolanovista, apesar de signatário do Manifesto de 1932, Lemme registra (escrevendo cincoenta anos depois do advento) que a questão dos avanços de uma sociedade não se encontra centrado nos modelos pedagógicos 
da educação, os quais forjariam mudanças estruturais "Ao contrário, porém, somente quando alcançarmos um regime verdadeiramente democrático é que se criarão as condições para que possa florescer uma educação democrática, na qual prevaleça o preceito fundamental da democracia, que é a igualdade de oportunidades para todos". (2004b, p. 182).

O Manifesto de 1932, apesar das ressalvas, opera um leque de influências, como a referenciada na carta de 1934, declarando que a educação é um direito de todos, responsabilidade da família e do Estado. Quanto a gratuidade a Carta de 1934 é clara relativa a sua extensão. Por sua vez, a Constituição de 1937 foca o dever da educação na família e minimiza a gratuidade, assim, "O Estado novo se desincumbiu da educação pública através de sua legislação máxima, assumindo um papel subsidiário." (GUIRALDELLI JR., 1994, p. 81).

Ghiraldelli é enfático ao afirmar o status que toma a dualidade de ensino que se torna legalizado ao registrar que "[...] a intenção da Carta de 37 era manter um explícito dualismo educacional: os ricos proveriam seus estudos através do sistema público ou particular e os pobres, sem usufruir esses sistemas, deveriam se destinar às escolas profissionais." (Ibid, p. 82).

Ocorre, portanto uma hegemonia do pensamento conservador no contexto político o que irá influir para um modelo de educação restrito e também conservador. Os renovadores não deixaram de existir, mas, suas manifestações foram relativamente caladas.

A importância do Manifesto se configura como inquestionável. Dos autores pesquisados somente Azanha problematiza tal unanimidade entre os educadores. Conforme o autor, a importância "tem sido, algumas vezes, minimizada pela arrogância dos patrulheiros ideológicos, mas é fora de dúvida que se trata de um documento que constitui marco histórico na educação brasileira, por várias razões." (1999, p. 106). Interessante notar que este é o primeiro autor que pondera sobre isto. Dos educadores pesquisados vinculados ao campo da direita ou da esquerda, nenhum contestou a importância do Manifesto de 1932, relativizam a atuação dos Pioneiros, principalmente ao que se refere ao seu idealismo, mas destacam o documento como um marco, principalmente pela busca de organicidade da educação, até porque existe uma atualidade no Manifesto, a qual foi recuperada durante o Governo de Fernando Henrique Cardoso, visto sua originalidade, pois "continha um diagnóstico e era um indicador de rumos." (1999, p. 106).

\section{Considerações}

O período estudado (1920-1937) para referenciar o tempo atual, concentrado na educação pelo Plano de Desenvolvimento da Educação (PDE 2007), 80 anos após o Manifesto de 1932, apresenta semelhanças na perspectiva das misérias acumuladas em relação à educação e à distribuição/concentração de rendas no país. Assemelha-se também a concepção pedagógica que foi sendo adotada, escamoteando-se o tradicionalismo academicista.

Constatamos que no Manifesto de 1932 ocorre uma projeção de requerimentos ao governo e ao povo, ao governo com a esperança de encontrar um chefe esclarecido (como deveria ocorrer com Getulio Vargas em 1932) e ao povo para tentar convencê-lo da necessidade da educação e da sua defesa intransigente. Esta História tem se configurado como uma espécie de sinecura secular hereditária na qual os avanços educacionais são muito parcos em comparando com os avanços tecnológicos e econômicos do país. 
O Estado e seus aparelhos têm sofrido intempéries holocausticas, no sentido de parcos avanços e contundentes resfriamentos. Tanto o é que temos nos afastado cada vez mais do ideal de controle social e de uma sociedade genuinamente pública e democrática.

A concepção de escola redentora fez-se presente e ainda se faz presente, alimentando a "crença de amplos setores da sociedade civil de que, pela via da escolarização, não só o desenvolvimento individual como a correção das distorções econômicas, sociais e políticas se tornaria possível." (WARDE, 1982, p. 10).

Os renovadores permaneceram no campo das reformas paliativas, ou seja, como negociadores dentro da ordem. Oitenta anos se passaram do primeiro Manifesto e esta tendência ainda continua acentuada. Educadores progressistas compactuam com governos liberais acreditando nos pequenos avanços, os quais seriam melhores do que nenhum pequeno avanço. Há trinta anos escreveu Warde, como se estivesse redigindo hoje, a citação que tomo como se minha fosse: "Para o governo, fazer coro com os defensores da escola pública, gratuita e obrigatória - e elegê-los seus interlocutores - foi (e tem sido) a forma de definir o campo possível de negociações com alguns setores da sociedade civil." (p. 10-11). E estes setores em geral têm sido lideranças articuladas com movimentos sociais ou partidos com fidedignidade junto a diversas categorias.

Outro comentário instigante da apresentação do texto de Warde na Revista do ANDES, diz respeito à nossa apatia em relação ao desenvolvimento educacional em nosso país. "Recuperar a escola pública, ao que parece, continua sendo uma bandeira de luta válida para os educadores que hoje estão comprometidos com os interesses populares. Historicizar esta luta é importante para dar a ela o significado que o novo contexto político e econômico do país exige." (FATO e ANÁLISE, 1982, p. 7).

Ao que parece, no octogésimo aniversário do Manifesto de 1932 ainda estamos buscando construir uma educação de quantidade e de qualidade que atenda as camadas pobres da população, buscando construir e reconstruir a escola de caráter público. E pelo que constatamos, parece que ainda temos dificuldades severas de avançarmos neste rumo.

\section{Referências}

AZANHA, J. M. P. Planos e políticas de educação no Brasil: alguns pontos para reflexão. In: MENEZES, J. G. de C. (Org.). Estrutura e funcionamento da Educação Básica: leituras. São Paulo: Pioneira, 1999.

AZEVEDO, F. de. As conquistas da civilização e a inquietação do homem interior. In: MANIFESTOS dos pioneiros da Educação Nova (1932) e dos educadores (1959). Recife: Fundação Joaquim Nabuco, Editora Massangana, 2010. P. 13-29.

AZEVEDO, F. de. A educação e seus problemas. São Paulo: Melhoramentos, 1948.

BUFFA, E.; NOSELLA P. A educação negada. São Paulo: Cortez, 1991.

BRUNO, L. Gestão da educação: onde procurar o democrático? In: OLIVEIRA, D. A. E ROSAR, M. de F. F. Política e gestão da educação. Belo Horizonte: Autêntica, 2002.

CUNHA, Luiz Antônio Cunha. A organização do campo educacional: as Conferências de Educação. In: Educação \& Sociedade. Ano III, número 9, maio. São Paulo: Cortez: Autores Associados, 1981.

FILHO, O. J. de A. O Manifesto dos Pioneiros da Educação Nova de 1932: memória e imagens do manifesto nos livros didáticos de História da Educação. Disponível em: 
http://www.faced.ufu.br/colubhe06/anais/arquivos/194OrlandoJoseFilho.pdf. Acesso em 22 de fevereiro de 2012.

FREITAG, B. Escola, Estado e Sociedade. São Paulo: Moraes, 1986.

GADOTTI, M. Convocados, uma vez mais: rupturas, continuidade e desafios do PDE. São Paulo: Instituo Paulo Freire, 2008.

GERMANO, J. W. Estado Militar e educação no Brasil. São Paulo: Cortez, 1994.

GUIRALDELLI JR., P. História da Educação. São Paulo: Cortez, 1994.

HADDAD, F. Os manifestos. In: MANIFESTOS dos pioneiros da Educação Nova (1932) e dos educadores (1959). Recife: Fundação Joaquim Nabuco, Editora Massangana, 2010. P. 101-103.

O Plano de Desenvolvimento da Educação: razões, princípios e programas. Brasília: INEP, 2008.

IVASHITA, S. B. e VIEIRA, R. DE A. Os antecedentes do Manifesto dos Pioneiros da Educação Nova (1932). Disponível em:

http://www.histedbr.fae.unicamp.br/acer_histedbr/seminario/seminario8/_files/GuEVnTfr. pdf. Acesso em 22 de fevereiro de 2012.

LEMME, P. Memórias de um educador. Estudos de educação e perfis de educadores.

Brasília: INEP, 2004a.

LEMME, P. Memórias de um educador. Estudos de educação. Participação em Conferências e Congressos. Documentos. Brasília: INEP, 2004b.

LIMA, L. de O. Estórias da educação no Brasil: de Pombal a Passarinho. Rio de Janeiro: Editora Brasília, s/d.

MANIFESTO DOS EDUCADORES. Manifesto dos educadores: mais uma vez convocados. (Janeiro de 1959). In: Revista HISTEDBR On-line. Campinas, no. Especial, agosto de 2006, p. 205-220.

MANIFESTO DOS PIONEIROS. O Manifesto dos Pioneiros da Educação Nova. (1932). In: Revista HISTEDBR On-line. Campinas, no. Especial, agosto de 2006, p. 188-204. MÉSZÁROS, I. A educação para além do capital. São Paulo: Boitempo, 2005.

MUELLER, H. I. Mais uma vez convocados: intelectuais e políticas educacionais. Disponível em:

www.utp.br/Cadernos_de_Pesquisa/pdfs/cad_pesq4/14_mais_uma_vez_cp4.pdf. Acesso em 28 de março de 2012. (P. 229-241).

RIBEIRO, M. L. S. História da educação brasileira. São Paulo: Moraes. 1982.

ROMANELLI, O. de O. História da Educação no Brasil (1930/1973). Petrópolis: Vozes, 1987.

SANFELICE, J. L. O Manifesto dos Educadores (1959) à luz da História. In: Educação e Sociedade, vol.28, no. 99, maio/agosto de 2007. Campinas: CEDES, 2007. P. 542-557.

SANTOS, I. da S. F. dos, et al. Brasil, 1930-1961: Escola Nova, LDB e disputa entre escola pública e escola privada. In: Revista HISTEDBR On-line. Campinas, no. Especial, agosto de 2006, p. 131-149. 
SAVIANI, D. História das idéias pedagógicas no Brasil. Campinas: Autores Associados, 2010.

SHIROMA, E. O.; MORAES, M. C. M. de; EVANGELISTA, O. Política educacional. Rio de Janeiro: DP\&A, 2000.

SMITH, A. A riqueza das nações. São Paulo: Abril Cultural, 1983.

TEIXEIRA, A. Educação não é privilégio. Rio de Janeiro: Editora UFRJ, 1994.

VIEIRA, S. L. Educação e legislação ordinária - há razões para esperança? In: Em Aberto, ano 7, no. 38, abril/junho. Brasília: INEP, 1988.

WARDE, M. J. O Manifesto de 32: reconstrução educacional no Brasil. In: ANDE, ano 1, no. 5. . São Paulo: S/Ed., 1982.

Notas:

1 Docente na Faculdade de Educação da Universidade Federal de Uberlândia (UFU), atuando em licenciaturas e no PPGED. Pesquisador FAPEMIG e CNPq. Coordenador do Grupo de Pesquisa Estado, Democracia e Educação (GPEDE). Colaborador do Grupo de Pesquisa Trabalho, Educação e Formação Humana. Dentre outros organizou o livro "Estados, Políticas Educacionais e Gestão Compartilhada", editado pela Xamã, 2004, "Estado e políticas públicas em tempos de reforma" pela Alínea, 2010 e "Estdo e o Controle Social no Brasil”, EDUFU, 2011. Contato: boscodelima@gmail.com e bosco@faced.ufu.br.

${ }^{2}$ Para a autora os períodos estão assim constituídos: $1^{\circ}$. Período (1549 a 1808); $2^{\circ}$. Período (1808 a 1850); $3^{\circ}$. Período (1850 a 1870); 4º. Período (1870 a 1894); 5. Período (1894 a 1920); $6^{\circ}$. Período (1920 a 1937); $7^{\circ}$. Período (1937 a 1955) e $8^{\circ}$. Período (1555 a 1964).

${ }^{3}$ Ver Romanelli (1987, p. 129).

${ }^{4}$ Dos quais podemos citar Ivashita e Vieira, 2012; Santos et al., 2006; Filho, 2012.

${ }^{5}$ A I CNE ocorreu em 1927 na cidade de Curitiba, PR; a II em 1928 na cidade de Belo Horizonte, MG; a III em 1929 na cidade de São Paulo, SP; a IV em 1931 na cidade do Rio de Janeiro, RJ; a V entre 1932 e 1933, em Niterói, RJ e a VI em Fortaleza, CE, em 1934.

A V CNE talvez tenha sido a de resultados mais produtivos “[...] convocada para Niterói e realizada de 26 de dezembro de 1932 a 8 de janeiro de 1933. Seu objetivo principal era preparar sugestões que seriam oferecidas ao governo, para serem submetidas à Assembléia Constituinte, que deveria se reunir a partir de 1933, para votar a nova Carta Constitucional brasileira.” (LEMME, 2004a, p. 189).

${ }^{6}$ Decreto n. 2.208/97 regulamenta o $§ 2^{\circ}$ do artigo 36 e os artigos 39 a 42 da LDB 9.394/96.

Recebido em abril/2012

Aprovado em maio/2012 